\title{
The Use of Interactive Mobile Technology to Improve the Quality of Health Care Services in Private and Public Hospitals in Australia
}

\author{
https://doi.org/10.3991/ijim.v12i6.9204 \\ Shakir Karim( $\left.{ }^{\bowtie}\right)$, Ergun Gide \\ Central Queensland University, Australia \\ s. karimecqu.edu.au
}

\begin{abstract}
The research questions, "As an Australian, can we expect fully Mobile Technology integrated health care services in Australia? Is it possible everywhere in Australia?" A healthcare system whether private or public should provide comprehensive health care services all over in Australia including countryside and CBD. In addition, the term 'Mobile Technology integrated health care' refers to a healthcare system designed for electronic and smart devices which can be used anytime and anywhere in the world. This research paper examines 'how patients can access GPs, specialists, private and public hospitals in Australia', which provide interactive Mobile Technology based health services. The research has mainly used secondary research data analysis and methods to provide a broad investigation of the issues relevant to interactive Mobile Technology and health care system in Australia, the problems, problem factors, benefits and opportunities in the health care industry. The research is subject to academic journal articles, conference proceedings, academic text books, project reports, online media articles, corporation-based documents and other appropriate information, including a technology adoption or acceptance research model for Mobile Technology integrated health care system. The preliminary stage of the research findings show that the proposed integrated Mobile Technology model can be applied to the current health care system in Australia, particularly improving patients' smooth access to GPs, specialists, public and private hospitals. Finally, the Mobile Technology integrated health care system will ensure that the framework is user and environmentally friendly including positive and active interactions with all system functions.
\end{abstract}

Keywords-Interactive Mobile Technology, Quality, Health Care, Services, Hospitals, Australia

\section{$1 \quad$ Introduction}

Technology has become engrained in the daily lives of today's generation. People are often simultaneously blogging, playing video games, watching video clips, texting, or checking social network sites while preparing for daily activities. Interactive Technology services are an emerging and increasingly important part of the nation's digital 
economy. It facilitates the shift from the personal computer to off-site information storage, services and applications and enables growth in online participation and collaboration through the development of 'device-agnostic' services [1,34]. Interactive Mobile technologies have moved into a mature set of technological innovations in Australia. It is promising to create new levels of productivity through large-scale computing resources.

The significant number of Australian enterprises using Interactive Technology services has risen from 19 percent to almost one-third in 2014, as shown by data from the Australian Bureau of Statistics [2]. The figure had jumped to 31 percent of businesses in the year of 2015-16. The survey was conducted among 6750 businesses in Australia. Businesses are mostly signing up for cloud-based software products ( 85 percent), followed by storage capacity at 60 percent - a trend that continued from $2016[3,35]$.

This paper brings details about present adoption and responses of Interactive Technology adoption in Health Care services in public and private hospitals in Australia. In order to analyze this, a brief study is taking place in a developed country (Australia). This paper proves that there are some general factors for Interactive Technology and these factors are identified from a business perspective. The paper centres on Interactive Technology prospects and development, Interactive Technology systems in Australia and also some security and privacy issues. The paper also looks into successful approval for Interactive Technology Satisfaction.

\subsection{Purpose and Scope}

This paper focuses on the use of interactive technology in Health Care services in public and private hospitals in Australia. As a developed country, Australia is the chosen country for this paper. As a developed and potential country, Australia should focus on the key reasons below.

- To clearly communicate the essence of Interactive Technology.

- Huge number of educated workforce in Australia including young generation will be benefitted.

- These people can be trained for skilled improvement.

- Australian health professionals working overseas can share their skills and knowledge to Australian people and other countrymen.

- Identify the opportunities and risks of Interactive Technology in health care services.

- Examine the most important challenge such as security and privacy.

- Quick adoption of Interactive Technology adoption in Health Care services in public and private hospitals in Australian rural areas [4].

- Vocational and tertiary education industries in Australia are able to produce more IT and medical graduates each year.

- Australian researchers can research and do more paper publications on this sector.

- Australia has a huge opportunity to grow secured Interactive Technology in the health sector [4]. 


\subsection{Research Objectives}

The issues regarding Interactive Mobile Technology adoption in Health Care service in Public and private hospitals in Australia has enabled this paper to develop the following objectives:

- To identify the features and significance of Interactive Technology adoption in Health Care services in public and private hospitals in Australia.

- To define the current status of Interactive Technology adoption in Health Care services in public and private hospitals in Australia.

- To illustrate the development of Interactive Technology adoption in Health Care services in public and private hospitals in Australia.

- To identify the opportunities and potential risks of Interactive Technology adoption in Health Care services in public and private hospitals in Australia.

- Finding out the reasons of the steady improvement in Interactive Technology adoption in Health Care services in public and private hospitals in Australia.

- Categorising common security and privacy factors of Interactive Technology adoption in Health Care services in public and private hospitals in Australia.

- Finding how secured Interactive Technology can help in the health growth of Australia.

\subsection{Aims of the Research}

The aims of this research are as below:

- To provide private and public health services including hospitals and administration by Interactive Technology adoption in Health Care services in public and private hospitals in Australia.

- To provide quality health services and facilities to meet the needs and emergencies of Australians.

- Looking after the people from cure to prevention by Interactive Technology adoption in Health Care services in public and private hospitals in Australia.

- To apply legislations and regulations for public and private hospitals in Australia.

- Delivering Information Communication Technology (ICT) led Healthcare

- Health protection: responsible for surveillance and responsible for infectious diseases.

- Providing hospital building program

\section{$1.4 \quad$ Research Questions}

This paper answers the following questions about Interactive Technology adoption in Health Care services in public and private hospitals in Australia:

1. What is the background and current status of Interactive Mobile Technology adoption in Health Care services in public and private hospitals in Australia? 
2. What are the reasons of the late upgrading in Interactive Mobile Technology industry in Australia?

3. What is the current security and privacy status of Interactive Mobile Technology in SMEs of Australia?

4. What is the possibility of developing Interactive Mobile Technology adoption for service SMEs of Australia?

5. How secured Interactive Mobile Technology can help in the e-health growth of Australia?

\subsection{Context of the Study}

This section presents the previous journal papers and academic proceedings about Interactive Technology adoption in Health Care services in public and private hospitals in Australia. It also mainly focuses on the Australian environment and Interactive Mobile Technology.

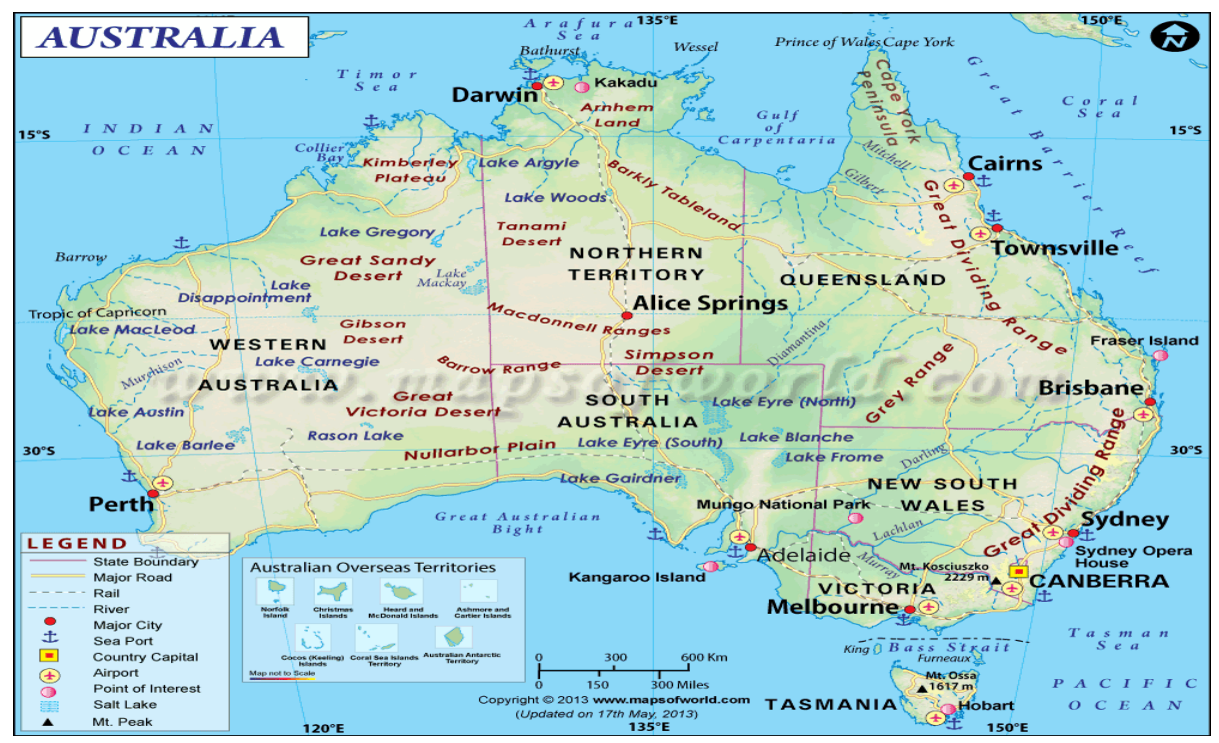

Fig. 1. Map of Australia [5]

As Figure 1 shows, Australia is a country and continent surrounded by the Indian and Pacific oceans. Its major cities - Sydney, Brisbane, Melbourne, Perth, and Adelaide - are coastal. Its capital, Canberra, is inland [6]. 


\section{Literature Review}

\subsection{Interactive (Mobile) Technology}

Interactive Technology refers to all forms of digital technology emphasising innovation and human-/user-centred approaches. It digitally facilitates interaction between people or allows for user content development or manipulation [7, 36, 37].

Below is a figure (Figure 2) that shows the process approach of e-Health services in Australia.

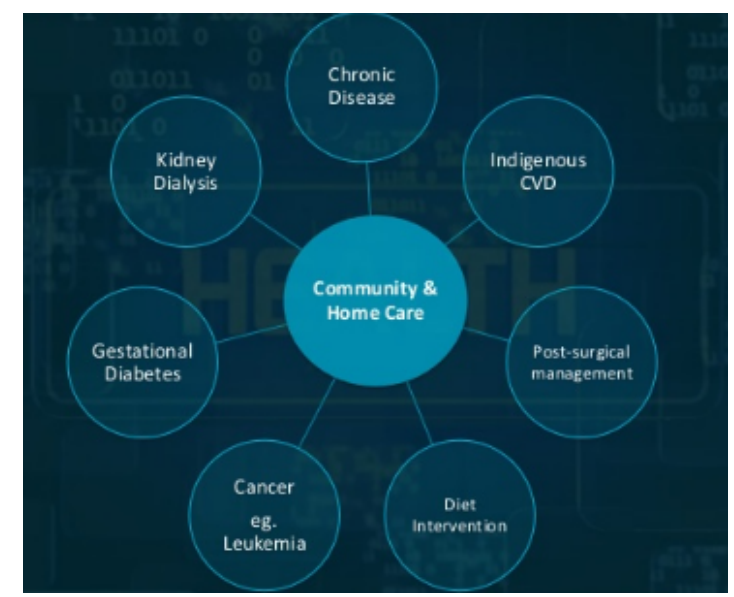

Fig. 2. The Current Activities in e-Health Services [8]

Below is a list that shows Interactive Technology oriented e-Health services in Australia [8].

- E-health records

- Health database and related standards

- Communications and messaging

- Decision Support Systems - DSS

- Prediction health planning tools

- Patients monitoring systems

- Mobile Health applications

- Portals and online resources

- Curing diseases and repairing damages

- Primary/community/acute/allied health services

- Special care services for aged/disabled/mental

- Preventive health and wellbeing

- Chronic disease management

- Health change strategies

- Risk factor modification

- Conventional health care 
One way to understand the benefits brought about by interactive technology is to compare linear and nonlinear multimedia. An example of linear multimedia is the typical presentation that combines video and sound, but without choices [9]. You watch it from beginning to end. Users are reacting to, not reacting with, what they see. Furthermore, there are a number of positive and negative issues in relation to Interactive Technology services $[10,39]$. The interactive network allows learners and organisations to test themselves anytime in a risk-free environment. It helps the users overcome a particular misunderstanding. As a result, ongoing self-testing gives a better sense of where the users stand [11]. In addition, it allows the information to be gathered in real time, and therefore the response to the customer can be timelier than with traditional media [11]. Of the negatives highlighted, SMEs and customers both note observations of security \& privacy issues and trust [12].

\subsection{Australia is ahead in Interactive Mobile Technology}

Interactive Mobile Technology is now predominant and is being adopted, not only for expediency and cost savings, but to meet strategic IT and business goals. Australian private and public hospitals at this stage are ahead of developing countries in the adoption of Interactive Technology. A big number of private and public hospitals in Australia are currently using mobile technology services in their service environment; better results in comparison to developing countries [13].

\subsection{Interactive Mobile Technology Sector of Australia in Future}

Interactive Mobile Technology is incredibly essential and appropriate to the developing health system of Australia and especially to the private and public hospitals. Australia has been financing greatly in developing its ICT sector, enhancing the presentation of its government and private sector. However, hospitals are also a significant component of the business society, and the flow of ICT into hospitals is important for the success of health informatics, progress, and the well-organised functioning of the information society [14].

\subsection{Australia is the Biggest Market for Mobile Technology in Health Services}

Australians unquestionably live in a technology developed country. Some of the supporting reasons are as below:

- The use of modern diagnostic equipment and data analytics in the health sector allow provision of customised health services that is much better targeted at the specific needs of individual patients [15].

- Mobile technology is epidemiologically useful when combined with other health and demographic details to improve quality of life [16].

- This is particularly important in industries such as healthcare where high security standards need to be achieved to ensure patient confidentiality [17]. 
- It is improving the health outcomes for all Australians.

- It also assists to provide personalised medicine, NLP for nursing handover, bioinformatics, ICT-enabled delivery of health services, industrialisation of biological experimentation [18].

\subsection{Why is Interactive Mobile Technology important?}

Successful Interactive Technology properly increases profits by more than $70 \%$. Allowing mobile integration in health sectors is a huge benefit for public and private health organisations, from users outlining to troubleshooting to scheme discovery. In the technology subdivision, using mobile technology helps to advance a strong consideration of the health services and medical products [19].

\subsection{Benefits of Interactive Mobile Technology for Health services in Australia}

Below segment highlights many other benefits of Interactive Mobile Technology adoption in Health Care services in public and private hospitals in Australia.

- Interactive Technology enables users to access a wide variety of digital information, including, video, television, high colour display, video and audio streaming, videoconferencing and electronic payment. 3G/4G mobile phone services offer voice services, $\mathrm{m}$-Internet service, online interactive video, quality images, data service, $\mathrm{m}$ commerce, m-payments, etc [20].

- Mobile access facilitates remote monitoring, follow up, prevention, remote assistance, diagnostics, m-prescriptions and patient access to their records [21].

- Interactive Technology in health care services delivers the best care; simple, flexible, personalized and secure connectivity for doctors, nurses, administrative staff and patients [22].

- By providing timely patient information such as diagnostic services and treatment results to the practitioners through wireless connection, it saves practitioners' time and effort spent on reviewing patient records on paper, traveling to fixed terminals or to a healthcare facility to collect information [22].

- Interactive Technology in health care services enables faster, more accurate patient assessments and offers more effective and timely delivery of care.

- Interactive Technology in health care services enables infrastructure for patient-centered care, improving clinical efficiency, and supporting evidence-based diagnosis and care delivery [23].

- Interactive Technology improves physical activity, nutrition, cognition and sleep [24].

- It reduces journey times, provides cost savings, reduces emissions and delivers an improved cyber experience.

- It monitors physiological and behavioural insights [24]

- It does health habit management and change strategies.

- It modifies health risk factors.

- Interactive Technology service providers can handle business scalability. 
- It helps to improve its administrative efficiency [3].

- Interactive Technology manages high-cost patients more effectively.

- Links patients to high-quality providers.

- Matches patients to optimal sites of care [20].

- Increases the speed and value of innovation in the health sector [21].

- Enhance outcomes and quality of health care.

- Interactive Technology allows employees to be more flexible in their work practices [3].

\subsection{Major Challenges and Considerations to Interactive Mobile Technology adoption in Health Care services in public and private hospitals in Australia}

Due to the thrive of Interactive Mobile Technology and the wide accessibility of both providers and tools, a significant number of challenges are being faced in Australia. These challenges are the key issues for future research directions. Challenges include user privacy, data security, data lock-in, availability, disaster recovery, performance, scalability, energy-efficiency, and programmability [3].

This paper highlights some of the constraints to Interactive Mobile Technology adoption in Health Care services in public and private hospitals in Australia. The list below shows the challenges in adopting Interactive Technology in e-Health services in Australia [1].

- Technology usability limitations

- Lack of digital literacy

- Impact of social isolation

- Differential engagement across care/service team

- Consumer empowerment and rise of expectations

- Non-sustainability of systems

- Problem of configurability

- Unfit technical components within health service systems

- Health safety and data security/privacy issues

- Health data quality issues

- Personalisation to subjects and their interactions with others

- Health data can be biased when conducting statistical analysis

- Data may be difficult to access, especially if it is held by private hospitals

- In the case of public hospitals, datasets are often available but difficult to find due to limited metadata

Furthermore,

- The security and privacy issue, untrustworthy behaviour of both end users and hospitals, misuse of commercial and intellectual property information.

- Approach to providing trust technologies is not appropriate in rural areas. 
- Another most serious concern is the possibility of confidentiality violations. Either maliciously or accidentally, hospital employees can tamper with or leak a company's data. Such actions can severely damage the reputation or finances of a company [24].

\section{Methodology}

\subsection{Identification of Scope of Study}

To accomplish the paper objectives, a systematic process is followed. The process begins with the identification of the project topic where studies were carried out to obtain enough information on the topic.

\subsection{Discussions to Collect Suggestions on Interactive Mobile Technology Adoption in Health Care Services in public and private hospitals in Australia}

Discussion is made between authors about the topic, impacts of Interactive Technology adoption in Health Care services in Australian public and private hospitals and barriers of Interactive Technology in health sectors in Australia and the future of Interactive Technology.

\subsection{Internet Search to Collect Data on Interactive Mobile Technology}

Authors have searched and collected data about Interactive Mobile Technology business growth and present situation of technologies in Australia.

\subsection{Research and Review}

This paper also analyses secondary academic resources from academic local and international journal articles including peer reviewed, academic conference proceedings, periodicals, academic text books, project reports, online media articles, corporate articles and annual reports.

\subsection{Qualitative Method and Data Collection (in the future)}

- In depth interviews will be carried out to bring together significant data from IT specialists, private and public-sector representatives, ICT students, and University School of Engineering and Technology academics. Authors will discuss the benefits and risks of Interactive Technology, the past and current situation of Interactive Technology, privacy and security satisfaction in Australia etc., with the interviewees. 
- The qualitative stage of data collection, the participants' communication process, their selection method, ethical clearance procedure, and the semi-structured and indepth individual interviews.

- An invitational letter will be sent prior to the consultation to increase an increased number of participants.

- The departments/faculties of the universities will be contacted by sending a request letter to identify the potential students. Thirty potential students will be chosen who will respond positively by email and telephone.

- Qualitative data analysis with relevant scale-based method will be used in future. Relevant computer software (NVivo) will be used.

- Furthermore, a technology adoption or acceptance research model for Mobile Technology integrated health care system will be in use.

- All of the transcripts will be categorised by alphabetical order of the interviewees' surname.

- Key issues will be checked systematically and noted in the list. Also, the researchers will discuss and prioritise the provider and the respondents who will do significant contribution.

\section{$4 \quad$ Data Collection and Key Findings}

This section defines qualitative results from face-to-face, comprehensive and indepth research interviews. The outcome is the result of the interviews with stakeholders such as IT experts, the government and non-government officials, academics and ICT students, identified as I1, I2, I3, I4, I5 .....G1, G2, G3, G4, G5 ......, A1, A2, A3, A4, $\mathrm{A} 5 \ldots$ and $\mathrm{S} 1, \mathrm{~S} 2, \mathrm{~S} 3, \mathrm{~S} 4, \mathrm{~S} 5 \ldots$

A list of the initial findings related to the key issues above and the information from the initial research.

- Interactive Mobile Technology can create comprehensive health opportunities in Australia.

- Mobile technology-based health care systems can be applied to a diverse array of fields, including care for pediatric and elderly patients, the supervision of chronic diseases, and the management of private health and fitness, among others.

- Australian people can raise much more Interactive Technology awareness among the people.

- Australian businesses are increasing Interactive Technology services.

- Communications and traditional health services in Australia are working side by side with Interactive Technology [26].

- ICT providers offer a range of services across all levels of the Interactive Technology service market across Australia.

- Without full and comprehensive security, Australia cannot access the full benefit and cannot establish and optimise full operation processes in Interactive Technology [27]. 
- Interactive Technology will be a key enabler for Health industries, and will also increase productivity and efficiency to achieve the highest economies.

- The efficiency of Interactive Technology makes it easy for the health development of Australia on an international rule [28].

- The Australian Federal Government can provide extended support through Interactive Technology [29].

- The Australian health sector, government agencies, and academic researchers need to have their security staff study the ICT environment, their ICT infrastructure and applications [30].

\section{The Significance of the Research}

This research is important for the people of Australia. This paper would be helpful for the policy makers in health sector for the country. Interactive Technology will become the public feature of a community and commercial life in Australia. This paper would benefit schools, TAFE and university students who want to become IT practitioners and professionals [31]. It will also be noteworthy for the public and private hospitals to take part and play a leading role in ICT and health sector in Australia.

\section{Conclusion and Recommendations}

Australia is implementing Interactive Technology in the health sector but security and privacy issues have yet to be addressed more satisfactorily. Australia needs to work more to rectify and solve all the complexities as well as develop Interactive Technology. The government should also work on resolving security and privacy issues in Interactive Technology by reviewing the current legislation and taking all necessary steps to ensure a supportive regulatory environment.

In addition, to gain the confidence on Interactive Technology, the overall computer and technology literacy must be developed. With that goal, the Australian Government has taken many local initiatives to develop Interactive Technology in the country, particularly in private and public hospitals. This would be a perfect ground for the development of Interactive Technology.

Furthermore, some more recommendations are given below:

- The Australian Government should take a quick approach and establish a new taskforce to security and privacy issues from the use of Interactive Mobile Technology.

- The Australian Government should review regularly the current legislation and take necessary steps to ensure a helpful supervisory environment.

- The Australian Department of Broadband Communications should review broadband policies to ensure about the acceptance of Interactive Technology.

- Australian universities should expand their units in Interactive Technology. They should seek the support from industry, government and university researchers on Interactive Technology. 
- The Australian Government should build and fund to actively boost the use of Interactive Technology.

- The Australian Government should ensure adequate funds to evaluate Interactive Technology services.

- Interactive Technology applications must be carefully evaluated and considered in regards to threats, risks and issues.

- Security, privacy and trust in Interactive Technology should always be available and present in Australia.

- IT infrastructure, internet access policies should constantly be fully secured everywhere including rural areas.

- The Australian Government should use faster processes to set up a national cybercrime unit to capture more cyber criminals [26].

- Determine a transition plan so professionals from a range of Health disciplines can be upskilled and cross skilled into cyber security professionals [31].

- Interactive Mobile Technology Services must always be trustworthy.

- In order for Interactive Technology to succeed, the Australian Government should promote international standards [32].

- Australian Government requires more funding for contributing to science and engineering research and produce applications which promise to benefit society as a whole [33].

- In Australia, there should be an agreement to offer individual researchers and research groups to have free access to advanced Interactive Mobile Technology resources [23].

- The Australian Government's program will assist researchers, entrepreneurs and inventors to convert ideas into successful commercial ventures in health sector by Interactive Mobile Technology.

- The Australian Government should fund more to encourage the use of Interactive Mobile Technology [19].

\section{$7 \quad$ References}

[1] 'Interactive Technology in Business Companies of Australia', 2017, AS and A Level/Business Studies/ICT in Business.

[2] Introducing mobile technologies in support of healthcare. Available from: https://www.researchgate.net/publication/279406752_Introducing_mobile_technologies_in_support_of_healthcare [accessed Jun 23 2018].

[3] Hage, E., Roo, J. P., Van Offenbeek, M. A. G., \& Boonstra, A. 2013, Implementation factors and their effect on e-Health service adoption in rural communities: A sys-tematic literature review. BMC Health Services Research, 13 (1), 1-16. https://doi.org/10.1186/1472-6963$\underline{13-19}$

[4] Foster, I., Zhao, Y., Raciu, I. and Lu, S., 2009, Interactive Technology and Grid Computing 360-Degree Compared. In Proceedings of Grid Computing Environ-ments Workshop, GCE '08, pp. 1-10.

[5] Maps of Australia 2015, viewed 27 March 2018, available at URL: https://www.google.com/search?q=Maps+of+World+2015\&rlz=1C1RLNS_enAU747AU7 
$47 \&$ tbm $=$ isch\&tbo $=$ u\&source $=$ univ $\&$ sa $=X \& v e d=0$ ahUKEwiVudnarvvbAhWmwFkKHZePCocQsAQIXw\&biw=1366\&bih $=662$

[6] 'Australia and WIFI Zone', viewed 2nd June 2018, available at URL: www.asiabarta24.com/front/singel/6/951

[7] 'Interactive Technology Race in Australia', viewed 9 May 2018, available at URL: http://www.smartcompany.com.au/growth/43407-australia-front-runner-in-Interactive Technology-race-report.html

[8] Digital Health Conference, CeBIT 2017, viewed 25 May 2018, available URL: https://www.slideshare.net/CeBITAustralia/cebit-australia-2017-prof-anthony-maeder-leveraging-emerging-ict-technologies-to-enable-new-health-services-and-new-models-ofcare-delivery

[9] Aymerich, F. M., Fenu, G. and Surcis, S., 2008, An approach to an Interactive Tech-nology network. In Proceedings of First International Conference on the Applica-tions of Digital Information and Web Technologies, ICADIWT 2008, pp. 113-118.

[10] Anderson, J. G. (2007). Social, ethical and legal barriers to e-health. International Journal of Medical Informatics, 76 (5), 480-483. https://doi.org/10.1016/j.ijmedinf.2006.09.016

[11] Avgar, A. C., Litwin, A. S., \& Pronovost, P. J. 2012. Drivers and barriers in health IT adoption: A proposed framework. Applied Clinical Informatics, 3(4), 488-500. http://doi.org/10.4338/ACI-07-R-0029

[12] Chowdhury, J. R., 2014, 'Information Technology in Australia', viewed 16 December 2017, available at URL: www.bdix.net

[13] Herricck, D. M., Gorman, L., \& Goodman, J. C. (2010), Health Information Tech-nology: Benefits and Problems, Retrieved from http://www.ncpa.org/pub/st327

[14] Hung, S. Y., Tsai, J. C. A., \& Chuang, C. C. 2014, Investigating primary health care nurses' intention to use information technology: An empirical study, Decision Support Systems, 57, 331-342. https://doi.org/10.1016/j.dss.2013.09.016

[15] 'Commonwealth Procurement Rules', 2017, viewed 22nd November 2017, available at URL: http://www.finance.gov.au/procurement/procurement-policy-andguidance/commonwealthprocurement-rules/

[16] 'Commonwealth Procurement Rules', 2017, viewed 22nd November 2017, available at URL: http://www.protectivesecurity.gov.au/pspf/Pages/default.aspx

[17] Howladar, M., Mohiuddin, M. \& Islam, M., 2014, 'Developing Online Shopping Intention among People: Australia Perspective', Journal of the International Institute for Science, Technology and Education, Vol 2, No.9, pp. 20-22

[18] Laumer, S., Maier, C., Eckhardt, A., \& Weitzel, T. 2015, User personality and re-sistance to mandatory information systems in organizations: A theoretical model and empirical test of dispositional resistance to change. Journal of Information Technology, 31, 67-82. https://doi.org/10.1057/jit.2015.17

[19] Baker, E. W., Al-Gahtani, S. S., \& Hubona, G. S. 2010, Cultural impacts on ac-ceptance and adoption of information technology in a developing country, Journal of Global Information Management (JGIM), 18 (3), 35-58. https://doi.org/10.4018/978-1-61350-480-2.ch003

[20] Technology and Australian Future, viewed 9 May 2018, available at URL: http://users.cecs.anu.edu.au/ $\sim$ williams/TAAF.pdf

[21] Boonstra, A., \& Broekhuis, M. (2010). Barriers to the acceptance of electronic med-ical records by physicians from systematic review to taxonomy and interventions. BMC Health Services Research, 10 (1), 231. https://doi.org/10.1186/1472-6963-10-231

[22] Buntin, M. B., Burke, M. F., Hoaglin, M. C., \& Blumenthal, D. 2011, The benefits of health information technology: a review of the recent literature shows predomi-nantly positive results, Health Affairs, 30 (3), 464-471. https://doi.org/10.1377/hlthaff.2011.0178 
[23] Buyya, R., Yeo, C. S. and Venugopal, S., 2008, Market-Oriented Interactive Tech-nology: Vision, Hype, and Reality for Delivering IT Services as Computing Utili-ties. In Proceedings of the 10th IEEE International Conference on High Perfor-mance Computing and Communications, pp. 5-13.

[24] Cybercrime: A growing Threat for Global Companies 2017, viewed 2nd November 2017, available at URL:https://www.rsm.global/insights/economic-insights/cyber-crime-growingthreat-global-companies

[25] Cybercrime- A growing concern for Australian Business 2017, viewed 2nd November 2017, available at URL: http://www.esvgroup.com.au/news/cybercrime-a-growing-concern-foraustralian-business/

[26] 'Cyber Crime', 2015, viewed 26 March 2018, available at URL: http://www.articlesbase.com/cyber-law-articles/cyber-crimes-539363.html

[27] Department of Broadband, Communications and the Digital Economy, 2009, 'Realising our broadband future', Conference held December 10-11 2009, details viewed on 22 June 2018, available at URL: http://www.broadbandfuture.gov.au/

[28] Department of Innovation, Industry, Science and Research, 2010, Super Science - Research data storage infrastructure; Implementation Discussion Paper, viewed on 22 June 2018, available at URL: http://www.innovation.gov.au/Section/science/Documents/DataStorageDiscussionpaper13April2010FINAL.pdf

[29] Garcia-Crespo, A., Colomo-Palacios, R., Gomez-Berbis, J.M., \& Mencke, M., 2009, BMR: Benchmarking Metrics Recommender for Personnel issues in Software Development Projects. International Journal of Computational Intelligence Systems, 2(3): pp. 257-267. https://doi.org/10.2991/ijcis.2009.2.3.7

[30] Garcia-Crespo, A., Colomo-Palacios, R., Gomez-Berbis, J.M., \& Ruiz-Mezcua, B., 2010, Semo: a framework for customer social networks analysis based on semantics. Journal of Information Technology, 25(2): pp. 178-188. https://doi.org/10.1057/jit.2010.1

[31] Nieboer, M. E., Van Hoof, J., Van Hout, A. M., Aarts, S., \& Wouters, E. J. M. 2014, Professional values, technology and future health care: The view of health care pro-fessionals, Technology in Society, 39, 10-17. https://doi.org/10.1016/j.techsoc.2014.05.003

[32] Rescorla, E., 2015, SSL and TLS, designing and building secure systems. Addison-Wesley.

[33] The future of Healthcare 2017, http://www.bain.com/publications/articles/the-future-ofhealthcare.aspx

[34] Akhondi, A., Yarmohammadian, M. Y. \& Haghani, F. (2015). Designing an e-learning curriculum for spelling on the basis of cognitive approach. Contemporary Educational Researches Journal, 5(1), 08-11. https://doi.org/10.18844/cerj.v5i1.9

[35] Cruz, C. O., Palomo, J. \& Figueroa-Domecq, C. (2017). Improving learning by moti-vating students to read the news using ICT. Global Journal of Business, Econom-ics and Management: Current Issues, 7(1), 89-98.

[36] Eyikara, E. \& Baykara, Z. G. (2017). The importance of simulation in nursing edu-cation. World Journal on Educational Technology: Current Issues, 9(1), 02-07.

[37] Lai, P. \& Zou, W. (2018). The application of virtual reality technology in medical education and training. Global Journal of Information Technology: Emerging Technologies. 8(1), 1015 .

[38] Celik, O. \& Yavuz, F. (2018). The effect of using mobile applications on literal and contextual vocabulary instruction. International Journal of Learning and Teach-ing. 10(2), 126136.

[39] Ceker, E. \& Uzunboylu, H. (2016). Comparing ICT Oriented Phd Research in Tur-key with Recent ICT Research Trends. Procedia Computer Science, 102, 90-97. https://doi.org/10.1016/j.procs.2016.09.374 
Paper-The Use of Interactive Mobile Technology to Improve the Quality of Health Care Services..

\section{Authors}

Shakir Karim and Ergun Gide are with Central Queensland University, Australia.

Article submitted 10 July 2018. Final acceptance 23 October 2018. Final version published as submitted by the authors. 